\title{
Indícios de sentidos e significados de feminilidade e de masculinidade em aulas de Educação Física
}

\author{
Vilma Canazart dos Santos \\ UNIMEP, Programa de Pós-graduação em Educação, Faculdade de Educação, \\ Piracicaba, SP, Brasil
}

\begin{abstract}
Resumo: O presente artigo trata de indícios de sentidos e significados de feminilidade e masculinidade em aulas de Educação Física. Os referenciais teóricos adotados estão ligados à perspectiva histórico-cultural (Lev Vigotski) e à concepção enunciativo-discursiva (Mikhail Bakhtin), além da literatura sobre o tema masculinidade e feminilidade e a Educação Física. Foram acompanhadas as aulas de dois professores, sendo uma do sexo feminino e outro do sexo masculino, em duas escolas da cidade de Sumaré/SP. Os/as alunos/as das $5^{\text {as }}$ séries - uma sala por escola - também constituíram o universo da pesquisa. Como forma de registro, foi utilizada a videogravação e o diário de campo. Foi possível identificar que muitas falas de alunas, alunos, professor e professora trazem indícios da internalização de valores e discursos, social e culturalmente construídos, que participam da institucionalização de certas normas, práticas e prioridades para cada gênero, sem, contudo, serem necessariamente percebidos.
\end{abstract}

Palavras-chave: Sentidos e significados. Feminilidade e masculinidade. Educação Física escolar.

\section{Trace of senses and meanings of femininity and masculinity in lessons of physical education}

\begin{abstract}
The article present treats of senses and meanings of femininity and masculinity in lessons of Physical Education. The theoretical adopted benchmarks are linked to the historical and cultural perspective (Lev Vygotsky) and design enunciative-discursive (Mikhail Bakhtin), beyond the literature on the subject femininity and masculinity and the Physical Education. I followed the lessons of two teachers, one female and one male, in two schools of the city of Sumaré/SP. The $5^{\text {th }}$ grades students- a room for school - also formed the universe of search. As a record was used to video and diary of field. It was possible to identify that many words of students, pupils, teachers and teacher bring evidence of the internalization of values and speeches, socially and culturally constructed, involved the institutionalization of certain standards, practices and priorities for each gender, without, however, not necessarily perceived.
\end{abstract}

Key Words: Senses and meanings. Femininity and masculinity. Physical Education classes.

\section{Feminilidade, masculinidade e Educação Física}

Alvo de constantes análises oriundas dos mais diversos campos do saber, talvez o corpo nunca tenha sido tão discutido, fragmentado e cultuado como nos últimos tempos. O corpo, inserido numa rede de relações sociais, é uma construção cultural, um conjunto de signos e marcas, produto de discursos e representações ${ }^{1}$ que buscam fixar sobre ele identidades. Identidades essas apontadas por Louro (1997) como sendo sexuais e de gênero.

A autora identifica como sexuais aquelas identidades que se constituiriam através das formas pelas quais os indivíduos vivem sua sexualidade, com parceiros/as do mesmo sexo, do sexo oposto, de ambos os sexos ou sem parceiros/as. Essa afirmação nos leva a tomar toda identidade sexual como um constructo

\footnotetext{
${ }^{1}$ O termo representação será entendido no trabalho como um modo de produção de significados na cultura, envolvendo as práticas de significação e os sistemas simbólicos através dos quais estes significados são construídos.
}

instável e mutável, em permanente estado de construção e transformação.

Para entender o gênero como constituinte das identidades dos indivíduos, Louro (1997, p.28) explicita que é possível pensar essas identidades de modo semelhante às sexuais, pois, "elas também estão continuamente se construindo e se transformando. Em suas relações sociais, os indivíduos vão se construindo como masculinos ou femininos, arranjando e desarranjando seus lugares sociais (...)". É mister salientar que essas construções e esses arranjos são sempre transitórios, transformando-se historicamente e na articulação com as histórias pessoais, as identidades sexuais dos indivíduos.

Desse modo, podemos considerar que, tanto na dinâmica do gênero como na dinâmica da sexualidade, as identidades não são dadas ou acabadas num determinado momento, mas elas estão sempre se constituindo social e historicamente e são, portanto, passíveis de transformação.

Segundo Louro (1997), ao aceitarmos que a construção de gênero é histórica e se faz incessantemente, estamos entendendo que as 
relações entre homens e mulheres, os discursos e as representações dessas relações estão em constante mudança.

Mas, afinal, o que vem a ser gênero?

Para Scott (1995, p.86), a definição de gênero repousa sobre a relação fundamental entre duas proposições: "o gênero é um elemento constitutivo de relações sociais baseadas nas diferenças percebidas entre os sexos, e gênero é uma forma primária de dar significado às relações de poder". Ao desenvolver essas proposições, completa dizendo que, "como um elemento constitutivo de relações sociais baseadas nas diferenças entre os sexos", o gênero implicaria quatro elementos: os símbolos culturalmente disponíveis numa sociedade que "evocam representações simbólicas"; os conceitos normativos (doutrinas religiosas, educativas, políticas, etc.) que "expressam interpretações dos significados dos símbolos"; as instituições sociais, a organização política, social e econômica; as identidades subjetivas - "as formas pelas quais as identidades genereficadas são substantivamente construídas" pelos indivíduos (p.86-88).

\section{Louro (1997, p.20-21) afirma que}

é necessário demonstrar que não são propriamente as características sexuais, mas é a forma como essas características são representadas ou valorizadas, aquilo que se diz ou pensa sobre elas que vai constituir, efetivamente, o que é feminino ou masculino em uma dada sociedade e em um dado momento histórico. Para que se compreenda o lugar e as relações de homens e mulheres numa sociedade importa observar não exatamente seus sexos, mas sim tudo o que socialmente se construiu sobre os sexos.

A autora ainda justifica que, ao dirigir o foco para o caráter social, não há a pretensão de negar a biologia dos corpos sexuados, mas busca-se enfatizar, deliberadamente, a construção social e histórica produzida sobre as características biológicas. Dessa forma, o conceito pretende se referir ao modo como as características sexuais são trazidas para a prática social e integradas ao processo histórico.

De acordo com Meyer (2003), o conceito de gênero propõe um afastamento de análises que tendem a focalizar apenas papéis e funções de mulheres e homens para aproximar-nos de abordagens mais amplas, que consideram que as instituições sociais, os conhecimentos, os símbolos, as normas e as políticas de uma sociedade são constituídos e atravessados por representações e pressupostos de feminino e de masculino, ao mesmo tempo em que estão implicados com a produção e ressignificação dessas representações.

O conceito passa a ser usado, então, conforme o dizer de Louro (1997), com um forte apelo relacional, já que é no âmbito das relações sociais que se constroem os gêneros. Nas palavras de Sousa e Altmann (1999), gênero é uma categoria relacional porque leva em conta o outro sexo, em presença ou ausência.

Ao mencionar o aspecto relacional do gênero, Scharagrodsky $(2004,2007)$ afirma que não se pode entender a feminilidade sem dar conta da masculinidade e vice-versa, pois os problemas vinculados à construção das feminilidades estão diretamente relacionados à construção das masculinidades. Isso implica que as mudanças em um coletivo geram necessariamente modificações sobre o outro coletivo, o que nos leva a considerar que os gêneros se fazem e se refazem continuamente ao longo da existência, e essas mudanças, na visão de Altmann (2006), evidenciam que polaridades de gênero e de sexualidade são socialmente construídas e, portanto, passíveis de problematização e desconstrução.

Para Louro (1997), na medida em que o conceito afirma o caráter social do feminino e do masculino, obriga aquelas/es que o empregam a levar em consideração as distintas sociedades e os diferentes momentos históricos de que estão tratando, o que passa a exigir que se pense de modo plural. Haveria conceitos de feminino e de masculino, social e historicamente diversos, transformando-se ao longo do tempo.

Dessa forma, este estudo foi fundamentado em posicionamentos que utilizam o conceito de gênero como uma construção sócio-histórica das diferenciações baseadas no sexo, o que vale dizer que a feminilidade e a masculinidade, ao contrário do que algumas correntes defendem, não são constituídas propriamente pelas características biológicas, mas são o produto, em constante processo de transformação, de tudo o que se diz ou representa de tais características.

Assim, tomamos feminilidade e masculinidade como construções culturais que se produzem e reproduzem socialmente e que não podem ser definidas fora de um contexto, ou seja, de condições históricas e culturais em que o indivíduo se constitui. Essa decisão conduz-nos a reiterar que feminilidade e masculinidade estão em permanente transformação, não sendo determinações fixas, e possuem uma multiplicidade de formas de ser homem ou mulher em nossa sociedade, multiplicidade esta em que afloram inúmeras tensões, conflitos e cenários.

Parafraseando Scharagrodsky (2007), somos o que somos não só porque nascemos com certos órgãos sexuais, mas também porque aprendemos a ser homens e mulheres de uma determinada maneira e em espaços, como no seio da família, no meio sociocultural e no âmbito escolar. Enfim, definir-nos por ser homem ou mulher faz parte de um processo cultural e de socialização.

No processo de transmissão cultural, além da família, a instituição escolar detém um papel 
muito importante, pois nela encontramos papéis atribuídos socialmente aos homens $e$ às mulheres, determinados através do tempo e culturalmente ancorados em diversas atividades, constituindo-se, portanto, em construções históricas e, como tais, modificáveis.

Sousa (1994), ao refletir sobre o ensino da Educação Física na escola, destaca a importância do processo de educação na construção de sujeitos masculinos e femininos e expõe que essa construção não se limita ao social, pois, corporalmente, cada ser humano aprende gestos, movimentos e falas a ele disseminados pela cultura.

Segundo Werneck (1996), as instituições educacionais utilizam-se de diferentes mecanismos, ora disseminando conteúdos e metodologias diferenciados para mulheres e homens, ora caracterizando sexualmente os gestos ou impondo papéis que reforcem e/ou produzam os sentidos de corpo frágil e emotivo feminino e de corpo forte e racional masculino, colaborando, assim, na inculcação de valores sexistas.

Nessa perspectiva, admite-se que as diferentes instituições e práticas sociais são constituídas pelos gêneros e são, também, constituintes destes (LOURO, 1997).

O corpo, como uma construção social e cultural, aparece fortemente modelado por práticas sociais de diferentes tipos, entre elas as práticas corporais e/ou esportivas. Conforme Scharagrodsky (2007, p.24), nas aulas de Educação Física, "o corpo se converte em um terreno de disputa no qual múltiplos significados se inscrevem sobre ele, configurando uma determinada cultura somática. Tal cultura somática nunca é fixa e acabada, mas é instável, dinâmica e se atualiza permanentemente".

De acordo com o autor supracitado, aceitar que as feminilidades e as masculinidades são heterogêneas, produto de construções sociais complexas e contraditórias, resulta em especial estímulo, já que isso implica que muitas práticas e discursos, fortemente arraigados no campo da Educação e da Educação Física, podem modificar-se e ser dotados de novos sentidos e significados.

No entanto, tratar de feminilidades e masculinidades na Educação e na Educação Física requer que antes se ressalte que os gestos corporais estão presentes não só nessas áreas, como também na vida cotidiana. Sousa e Altmann (1999) esclarecem ainda que os fatores sociais determinam as expectativas de uma pessoa em relação a um ou mais indivíduos e que, dentro de diversas culturas, a forma de educar homens e mulheres presume uma construção social e corporal, implicando diretamente no processo de ensino/aprendizagem de valores como conhecimentos, costumes e gestos corporais tidos como femininos ou masculinos.

Ainda que a preocupação com as identidades de gênero esteja presente em todas as situações escolares, afirmamos que talvez ela se torne particularmente explícita numa área que está, constantemente, voltada para o domínio do corpo, pois, conforme relata Louro (1997), muitos/as estudiosos/as do gênero, em especial aqueles/as que se dedicam ao estudo das masculinidades, destacam o papel dos esportes e da ginástica no processo de formação dos indivíduos.

\section{Educação Física: da dimensão biológica à dimensão cultural}

Considerando a história da Educação Física brasileira, o olhar que foi dirigido ao corpo no final do século XVIII apresentava um caráter conservador e utilitário, uma vez que, filha do positivismo, a Educação Física absorveu a sua concepção de ser humano como um ser puramente biológico e orgânico, que precisa ser disciplinado.

Em suas primeiras tentativas para compor o universo escolar brasileiro, segundo Soares (2001), a Educação Física surgiu como promotora da saúde física, da higiene física e mental, da educação moral e da regeneração da raça. Assim, atividades ginásticas foram propostas diferentemente aos homens e às mulheres, de modo a fixar no corpo da mulher possibilidades e restrições, remetendo a uma naturalização dos papéis sexuais culturalmente instituídos para um e outro sexo.

Enquanto fruto da biologização, a Educação Física, idealizada e realizada pelos médicos higienistas, foi utilizada como instrumento de aprimoramento da saúde física e moral e atuou na preparação do corpo feminino para o desempenho de sua tarefa de reprodução, reforçando, assim, o ideário burguês sobre os espaços e papéis sociais permitidos à mulher ocupar e desempenhar. Atuou, também, tanto na preparação do corpo do soldado, fazendo-o útil à pátria, quanto no corpo do trabalhador manual, tornando-o mais útil ao capital. Enfim, ela se fez protagonista de um corpo saudável, robusto, disciplinado e de uma sociedade asséptica, limpa, ordenada e moralizada (SOARES, 2001).

A história da Educação Física no Brasil, conforme Daolio (1997), para além de um somatório de elementos responsáveis pela produção e reprodução de determinados comportamentos, foi influenciando a construção de um imaginário social referente ao corpo, que se expressa no conjunto das ações e representações dos indivíduos até os dias de hoje.

Ancorado na análise antropológica, Daolio (1995, 1997, 2004, 2005) passa a vislumbrar uma prática de Educação Física que considera o 
caráter cultural do povo. Promove, assim, discussões que aprofundam questões relacionadas com a cultura para uma área que, até há pouco tempo, apoiava-se, predominantemente, nas ciências biológicas.

Dessa forma, Daolio (1995, 1997, 2004, 2005) concebe a cultura como o principal conceito para a Educação Física, uma vez que todas as manifestações corporais humanas são geradas na dinâmica cultural, com expressões diversas e significados próprios no contexto de grupos culturais específicos.

Enfim, a proposição que elege a cultura como aspecto fundante permite dimensionar a Educação Física, "tomando-a não mais como área que trata apenas do corpo e do movimento para constituir-se em área que trata do ser humano nas suas manifestações culturais relacionadas ao corpo" (DAOLIO, 2004, p.70).

As discussões sobre cultura procuram, conforme nos aponta Nogueira (2005), compreender a Educação Física como uma produção cultural e aguçar as nossas sensibilidades para o entendimento sobre como as práticas corporais fazem parte de um contexto social.

No que tange às apropriações da dimensão cultural no âmbito pedagógico, torna-se importante, conforme os dizeres de Noqueira (2005, p.208), "aceitar o corpo, as práticas corporais e a própria disciplina Educação Física como carregados de sentidos e significados da sociedade", levando a um olhar que nos remete a reiterar que as práticas e os conteúdos presentes na cultura corporal de movimento são produções humanas carregadas de significação.

Desse modo, vivemos em cenários de cultura, os quais são incorporados nas relações estabelecidas com outras pessoas para fazer com que a experiência individual faça do ser humano um ser cultural. Entretanto, não nos basta apenas incorporar, criar coisas, sendo preciso também significar tudo aquilo que criamos, reproduzimos e produzimos. O mais importante é a nossa capacidade de atribuir significados múltiplos e sentidos transformáveis ao que fazemos, aos modos sociais pelos quais fazemos.

Nessa perspectiva, é imprescindível que o/a professor/a de Educação Física acredite que o conjunto de posturas, valores e movimentos corporais é constituído de valores representativos e princípios culturais de uma determinada sociedade e que, portanto, atuar no corpo implica atuar na sociedade na qual este corpo está inserido.

É nesse contexto que insiro a temática da feminilidade e masculinidade, pois o conjunto de símbolos, códigos, sentidos e significados que se produzem e reproduzem dinamicamente nos esportes, jogos, danças, ginásticas e lutas influenciam, delimitam, dinamizam e/ou constrangem múltiplas concepções de feminilidade e masculinidade que marcam a constituição dos indivíduos em nossa sociedade.

\section{A constituição da subjetividade pela alteridade}

Os referenciais teóricos adotados na pesquisa para análise das falas dos indivíduos estão ligados à perspectiva histórico-cultural e à concepção enunciativo-discursiva. Esses referenciais se fazem necessários e pertinentes, uma vez que o almejado neste trabalho é identificar e analisar os processos cotidianos de produção de significação de feminilidade e masculinidade presentes em aulas de Educação Física.

No que tange à perspectiva histórico-cultural, apoiei em seu principal representante - Vigotski, que busca a sustentação de teorias sobre os processos humanos, possibilitando, assim, discussões acerca do desenvolvimento humano e suas especificidades.

Quanto à concepção enunciativo-discursiva, foi interessante e profícuo apoiar na perspectiva de Bakhtin (1990, 1993, 2003) acerca do psiquismo e da ideologia, à medida que se buscou teórica e empiricamente analisar os enunciados, a fala "como artefato cultural e como uma realidade histórica específica que permeia as relações humanas e produz sentidos" (SMOLKA, 1992, p.330).

O que os une, de acordo com Lima (2005), é o interesse em compreender os processos humanos e constituição da subjetividade, a qual tem sua gênese nas relações com o outro e com a cultura. Essas relações geram efeitos singulares em cada sujeito, pois sua história pessoal vai sendo forjada na sua relação com o mundo, com o(s) outro(s) e com ele próprio, mostrando assim horizontes de possibilidades que se abrem.

Dessa forma, Vigotski $(1993,1995)$ e Bakhtin (1990, 1993, 2003) compartilham de ideias como: a importância do outro e da cultura na constituição da subjetividade; a linguagem e os discursos estão primeiramente orientados para $\mathrm{o}$ (s) outro(s); a polissemia se produz no contexto interlocutivo, portanto os sentidos estão em permanente construção e impregnados pelas formas culturais; e, principalmente, a interdependência entre pensamento e linguagem, possuindo ambos um traço social.

\section{A constituição do funcionamento humano}

Vigotski (1995) apresenta como tese fundamental que a gênese das funções psicológicas está nas relações com o outro e com a cultura, sendo a constituição do funcionamento 
humano socialmente mediada, num curso de desenvolvimento que abrange evoluções e, sobretudo, revoluções.

Segundo Góes (2000, p.12), ao ter em vista a crença no papel das relações concretas da vida social, Vigotski "concebe o estudo do homem enquanto ser que se constitui imerso na cultura nas experiências coletivas e práticas sociais - e como produtor-intérprete de sistemas semióticos".

Na formação da consciência, Vigotski (1993, 1995) ressalta a implicação de dois fatores: a internalização e a mediação.

O processo de internalização, no olhar de Smolka (2000, p.27), é caracterizado como um construto teórico central no âmbito da perspectiva histórico-cultural, que se refere ao processo de desenvolvimento e aprendizagem humana como incorporação da cultura, como domínio dos modos culturais de agir, pensar, de se relacionar com outros, consigo mesmo (...)". Nessa perspectiva, Smolka (2000) expõe que Vigotski muda o foco da análise psicológica ao colocar que não é o que o indivíduo é, a priori, que explica seus modos de se relacionar com os outros, mas são as relações sociais nas quais ele está envolvido que podem explicar seus modos de ser, de agir, de pensar, de relacionar-se.

Pode-se dizer assim que a internalização é a criação de um espaço interno ainda não existente - consciência - e que continua a se formar através das relações sociais.

A relação indivíduo-sociedade é dialética e, portanto, não se pode compreender o processo de formação psíquica pelas relações sociais, a não ser que se considere a produção simultânea de signos e sentidos, relacionada à constituição de sujeitos (SMOLKA, 2000). Como tais, os sujeitos são afetados de diferentes modos por signos e sentidos produzidos nas relações com os outros como também na história dessas relações. Desse modo, a apropriação está relacionada a diferentes modos de participação nas práticas sociais e possibilidades de produção de sentido, o que nos leva a considerar que nem tudo que é transmitido torna-se necessariamente internalizado. É nessas práticas, como relações significativas, que o sujeito se constitui.

Toda internalização, apropriação das formas especificamente humanas, se dá por meio da mediação, havendo assim uma relação dialética entre internalização e mediação. O processo de mediação implica o uso de ferramentas culturais, como a linguagem e outros meios, através dos quais o sujeito domina e se apropria dos conceitos, das ideias, das práticas, das competências e de todas as outras possíveis aprendizagens.

\section{Linguagem: um instrumento semiótico}

O ser humano, para Vigotski (1995), emerge como indivíduo conforme vai imergindo na cultura e a sua singularidade vai sendo constituída nas/pelas relações sociais. Conforme dito, a atividade mental do homem - seu psiquismo constitui-se na relação com o outro, apresentando essa relação social um caráter semiótico.

Para Luria (1979), a linguagem é a segunda condição que leva à formação da atividade consciente. Ela é um meio de comunicação pelo qual $o$ ser humano conserva, transmite informações e assimila a experiência acumulada por gerações, destacando assim a linguagem verbal.

O surgimento da linguagem imprime três mudanças essenciais à atividade consciente do ser humano, de acordo com Luria (1979). A primeira consiste em que a linguagem duplica 0 mundo perceptível, permite conservar a informação recebida do mundo exterior e cria um mundo de imagens interiores. Outro papel da linguagem na formação da consciência consiste em que as palavras de uma língua não apenas indicam determinadas coisas, como relacionam as coisas perceptíveis a determinadas categorias (abstração). Essa possibilidade de assegurar o processo de abstração e generalização representa a segunda contribuição da linguagem para a formação da consciência.

Além de configurar um meio de comunicação, ela também é o veículo mais importante do pensamento, o que leva a fundamentar a terceira função da linguagem, segundo o autor mencionado. Para ele, a linguagem "é o veículo fundamental de transmissão de informações, que se formou na história social da humanidade" (1979, p.81).

Corroborando os dizeres de Luria, Baquero (1998) afirma que a linguagem pode cumprir diferentes funções, porém ressalta apenas a função de ser inicialmente comunicativa, um meio de expressão e comunicação social e de constituir-se no instrumento central da mediação, ou seja, é por meio dela que o psiquismo humano é socialmente formado e culturalmente transmitido. Assim, a linguagem ocupa o estatuto central na teoria de Vigotski, como parte e mediadora da ação humana.

Martins (1997) pontua que quando a linguagem se dirige aos outros, o pensamento torna-se passível de partilha. Essa acessibilidade do pensamento manifesta-se, pois, na e pela linguagem, expressando, ao mesmo tempo, muitos outros aspectos da personalidade do sujeito.

Em seu livro "Pensamento e Linguagem", Vigotski (1993) faz considerações quanto à centralidade do signo na formação dos processos humanos, afirmando que a palavra é o microcosmo da consciência humana. Ele também salienta a noção de sentido da palavra, concebendo-a como fundamental para a 
compreensão dos significados da linguagem verbal.

Vigotski (1993) faz do significado das palavras a unidade de análise de suas pesquisas, e a palavra, sendo um "microcosmo da consciência", contém em seu significado a possibilidade de analisar as relações entre pensamento e linguagem, as quais caracterizam-se pela interdependência entre eles. Assim, Góes e Cruz (2006, p.36) apontam o significado como pertencente "às esferas tanto do pensamento quanto da linguagem, pois, se o pensamento se vincula à palavra e nela encarna-se, a palavra só existe se sustentada pelo pensamento". Entretanto, não podemos esquecer que a significação não está na palavra, mas é o efeito da interlocução, como apontam os estudos de Bakhtin.

Quanto ao significado e sentido, Martins (1997) afirma que Vigotski estabelece uma importante distinção entre eles, apresentando que aquilo que é convencionalmente estabelecido pelo social é o significado do signo lingüístico, enquanto o sentido é o signo interpretado pelo sujeito histórico, dentro de seu tempo, espaço e contexto concreto de vida social.

Portanto, a construção de significados e sentidos tem lugar num contexto de comunicação interpessoal. Esses processos são fortemente impregnados e orientados pelas formas culturais existentes nessa comunicação que sofrem constantes modificações.

Além de referenciar Vigotski (1993, 1995), também buscamos fundamentação em Bakhtin (1990, 1993, 2003), que compartilha da ideia do autor supracitado, de que a consciência humana organiza-se e desenvolve-se através das relações sociais. Para ele, mesmo que a atividade mental não seja visível, ela é exprimível para o outro e igualmente compreensível por signos, sendo a palavra um signo ideológico por excelência.

\section{Os signos em Bakhtin}

$\mathrm{Na}$ concepção de Vigotski e de Bakhtin, cada sujeito torna-se ele mesmo por meio do outro, o que atribui à interação verbal um papel central. Como material semiótico da vida interior, signo social, Bakhtin, assim como Vigotski, elege a palavra - o signo ideológico por excelência, pois as palavras captam e indiciam os processos de constituição dos sentidos e dos sujeitos.

Por ideologia, Bakhtin (1990) refere-se a toda produção de significação, tudo que é um signo, possuindo, portanto, um valor semiótico e um significado. Ao se referir ao signo, o autor citado afirma que esse é um fenômeno do mundo exterior, tem uma encarnação material e só aparece em um terreno interindividual, emergindo do processo de interação entre uma consciência individual e uma outra, ou seja, é materializado na comunicação social.
Essa comunicação social pode ser dividida em signos ideológicos verbais e não-verbais; os verbais são representados pelas palavras - tidas como material flexível e privilegiado da comunicação na vida cotidiana, e os não-verbais possuem relação estreita com as palavras em todo o ato consciente.

Assim, para Bakhtin (1990, p.52), todo gesto, grito, movimento do corpo "pode tornar-se material para a expressão da atividade psíquica, posto que tudo pode adquirir um valor semiótico, tudo pode tornar-se expressivo", o que em outras palavras quer dizer que tudo pode adquirir um significado e um sentido quando inserido em um contexto.

A linguagem torna-se, desse modo, constitutiva do pensamento, da experiência humana e fundamental na construção da história.

\section{Bakhtin e as práticas discursivas}

Ao eleger a palavra como signo ideológico, Bakhtin acaba por valorizar a fala, a enunciação, como unidade de base da língua. A enunciação é um produto da interação de dois indivíduos socialmente organizados, sendo também socialmente dirigida e determinada pela situação social mais imediata e pelo meio social.

Em virtude de a enunciação ser de natureza social, o seu centro organizador é exterior, está situado no meio social, o que importa dizer que a significação não está na palavra, ela é estabelecida de fora para dentro, na relação com o outro.

A enunciação constitui uma fração na corrente da comunicação verbal, sendo unidades reais da cadeia verbal, e o diálogo é o produto da interação social, é o efeito da interação de um falante e um ouvinte, na qual este ocupa em relação àquele uma posição ativamente responsiva ao longo de todo o processo de audição e compreensão da fala.

No entanto, o enunciado já apresenta limites precisos, mas no âmbito desses limites ele reflete o processo do discurso, os enunciados dos outros e os elos precedentes da cadeia discursiva. O enunciado não pode ser separado dos elos precedentes que o determinam, porém ele não está ligado apenas aos elos precedentes, mas também aos subseqüentes da cadeia discursiva, pois o papel dos outros (ouvintes) é grande, já que estes são participantes ativos da cadeia (BAKHTIN, 2003). Referidos elos geram nos enunciados, além das atitudes responsivas, ressonâncias dialógicas, ou seja, os enunciados estão cheios de palavras alheias, palavras estas que se apresentam como uma arena de luta, ponto de encontro e confronto de múltiplas vozes: vozes dos outros, vozes da história, que ecoam em nós, nos constituem e nos significam.

A multiplicidade de vozes, chamada por Bakhtin de polifonia, aliada à multiplicidade de sentidos da palavra, chamada por Vigotski de 
polissemia, constituem cada indivíduo de modo a configurar uma dispersão na unidade. Nas palavras de Fontana (2003, p.64), "somos uma multiplicidade de papéis e de lugares sociais internalizados que também se harmonizam e entram em choque. (...) Muitos em um".

Nessa perspectiva, os discursos não podem ser analisados sem conflitos e tensões, pois os lugares de onde eles são produzidos não são necessariamente harmônicos e de consensos, o que nos leva a corroborar que a nossa própria ideia nasce e se forma no processo de interação e luta com os pensamentos dos outros.

Assim, as concepções de Vigotski e Bakhtin expostas anteriormente encontram-se entrelaçadas na pesquisa, sendo abordadas ao longo das análises realizadas, com o auxílio de outros/as autores/as que nos ajudam na compreensão dos sentidos, dos significados e dos detalhes captados, contribuindo para o enriquecimento teórico da pesquisa.

\section{Sujeitos da pesquisa}

A pesquisa foi realizada com dois professores, sendo uma do sexo feminino e outro do sexo masculino, em duas escolas de médio porte da rede estadual de São Paulo situadas em regiões periféricas da cidade de Sumaré. Tanto a professora como o professor ingressou na rede estadual no ano de 2006 e ministram aulas para o ensino fundamental. Os/as alunos/as também constituíram o universo desta pesquisa, pois o jogo de relações sociais envolve outros/as atores/atrizes além do/a professor/a, que, no caso, são os/as alunos/as. No entanto, participaram apenas os/as alunos/as da $5^{\mathrm{a}}$ série uma sala de cada escola, perfazendo um total de 69 alunos/as, sendo 30 meninas e 39 meninos, com a média de idade de 13 anos. Na escolha dessa série e da sala foi levada em consideração tanto a programação a ser desenvolvida na disciplina quanto a compatibilidade de horários entre o/a professor/a e a pesquisadora.

\section{Construção de dados}

Para a construção de dados foi utilizada a observação direta das aulas de Educação Física durante as quais buscou-se focalizar a tríade professor/a, aluno/a e atividade e as interações professor/a-alunos/as e alunos/as-alunos/as. Como forma de registro foi utilizada a videogravação e o diário de campo, com prévia autorização do/a diretor/a, professor/a de Educação Física e dos/as responsáveis pelos/as alunos/as.

A etapa da observação foi desenvolvida em quatro semanas, totalizando nove sessões de filmagens. Cinco sessões, com duração média de 45 minutos cada foram realizadas junto à professora e nas outras quatro, com duração média de uma hora e vinte minutos cada, houve o acompanhamento das aulas do professor. Outro recurso utilizado foi o diário de campo, no qual foram feitos alguns registros sobre o ambiente da sala de aula, o conteúdo desenvolvido, a metodologia empregada pelo/a professor/a, os diálogos entre os/as alunos/as e outras observações pertinentes à pesquisa.

A etapa seguinte consistiu na transcrição de todas as aulas de Educação Física videogravadas, com posterior recorte de alguns episódios a serem analisados à luz do referencial teórico. Na transcrição das fitas, as falas foram editadas com o objetivo de fazer sentido para o leitor estranho ao grupo e, buscando resguardar o anonimato dos indivíduos envolvidos, houve a atribuição de nomes fictícios a estes.

As diversas leituras das transcrições, aliadas à interlocução com a literatura e o referencial teórico, possibilitaram a organização e apresentação dos episódios por aproximações de eixos, a fim de analisá-los como sentidos possíveis - compreendidos e captados por intermédio das enunciações dos sujeitos - nas condições sociais em que foram produzidos, visando a uma possível contribuição para a área de conhecimento em questão.

\section{Examinando os achados}

A especificidade do trabalho está no recorte feito acerca dos processos cotidianos de produção de significação de feminilidade e masculinidade em um espaço social específico e a constituição do ser humano, segundo a teoria de Vigotski $(1993,1995)$ e a concepção enunciativo-discursiva, buscando a fala como uma realidade histórica específica que permeia as relações humanas e produz sentidos, de acordo com Bakhtin $(1993,1999,2003)$. Vale explicitar que, nos episódios, não são as situações em si que interessam, mas as relações dialógicas, entendidas como relações de sentidos que decorrem da responsividade inerente a todo e qualquer ato enunciativo, como nos diz Bakhtin (1993).

As leituras dos episódios, aliadas à interlocução com a bibliografia sobre o tema feminilidade e masculinidade, Educação Física e o referencial teórico adotado para a análise dos episódios, possibilitaram a construção de quatro eixos temáticos, entretanto, neste artigo será apresentado e discutido apenas um eixo: aquele que trata dos processos cotidianos de produção de significação de feminilidade e masculinidade.

Sabendo que a produção de significação implica múltiplos sentidos, significados, direções e relações, saliento que, como pesquisadora, busquei traçar alguns indícios de sentidos de feminilidade e masculinidade presentes em aulas de Educação Física.

\section{As primeiras impressões: indícios de sentidos e significados de feminilidade e de masculinidade}




\section{socialmente construídos e} culturalmente transmitidos

\section{Episódio 1:}

O professor chega à sala, fala o que eles/as irão fazer na aula e, após fazer a chamada, pede aos/as alunos/as para abrirem os cadernos que ele vai vistar. Enquanto o professor passa de carteira em carteira olhando os cadernos ...

Luana: De quem é esse apontador? (ninguém se manifesta). Eu vou jogar no lixo.

Wesley: É meu.

Luana: Não é! Ele é rosa.

\section{Episódio 2:}

A professora chega à sala de aula, faz a chamada e pede aos/as alunos/as que subam para a quadra. Na quadra, ela propõe um jogo chamado base quatro ${ }^{2}$ e divide a classe em duas equipes mistas. Para a composição das equipes, a professora chama por nome, de forma a tentar equilibrá-las. O jogo inicia-se e no seu decorrer ouço uma menina - Débora - falar que não consegue chutar forte. Aproximo-me dela e pergunto:

Pesquisadora: Você não consegue chutar forte por quê?

Débora: Porque a gente é mais sensível.

\section{Episódio 3:}

No pátio, a professora pede aos/às alunos/as para sentarem em círculo, conversa sobre as aulas do bimestre e faz o encerramento do ano letivo.

\section{[...]}

Professora: Meninas, não querem falar nada, que não faziam nada; tinha que ficar puxando, implorando para participar. Muito ruim fazer Educação Física? Muito ruim, Ellen?

Ellen: Não.

Professora: Não? Só que tem que tomar cuidado, né?! Porque a bola machuca.

A presença de características socialmente construídas e associadas ao sexo é uma

\footnotetext{
2 O jogo base quatro é composto por duas equipes ( $A$ e $B$ ), sendo que não há um limite máximo de integrantes e é jogado com uma bola. Uma das equipes (A) deve ficar na área delimitada para o chute da bola e a outra equipe (B) deve colocar alguém para ser o lançador da bola para a equipe $A$, enquanto os seus demais participantes se espalham pelo espaço de jogo - previamente delimitado - para recuperar o mais rapidamente a bola chutada pela equipe $A$, pois esta equipe, ao chutar, terá que correr pelas bases; ao passar pela quarta base, marca um ponto para a sua equipe. Porém, se a bola for recuperada pela equipe $B$, sendo entregue ao lançador antes que o participante da equipe $A$ esteja em uma das bases, este será considerado eliminado do jogo. Caso o participante esteja em uma das bases quando a bola for entregue ao lançador, ele estará salvo e poderá passar pelas outras bases quando o próximo participante de sua equipe chutar a bola. Assim que todos os participantes chutarem, as equipes trocam de lugar.
}

constante nos episódios transcritos. No primeiro, a fala de Luana deixa indícios de que há, para ela, uma relação entre a cor do objeto e o sexo do indivíduo. Assim, ela presume que o fato de o apontador ser rosa é indicativo de que não pertenceria a um menino, uma vez que, de acordo com algumas construções sociais, essa cor seria de menina.

No segundo episódio, a fala da Débora - "a gente é mais sensível" nos leva a algumas reflexões, como: quem seria essa gente? A quem ela está se referindo? Pelo advérbio utilizado, Débora deixa explícita uma comparação, ao mesmo tempo em que ficam implícitos, a partir do adjetivo, indícios de binarismos, mas com quem? Homens e mulheres?

$\mathrm{O}$ enunciado da professora direcionado à Ellen no episódio 3 - "Só que tem que tomar cuidado, né?! Porque a bola machuca." - pode, de uma certa forma, ratificar a opinião da Débora, uma vez que ela acaba por reproduzir um sentido de sensibilidade e fragilidade da mulher perante as vivências/práticas corporais. Tal enunciado ainda nos leva a indagar: e o homem, não se machuca também?

Nesses processos de interlocução, as falas deixam-nos indícios de que atributos como sensibilidade e delicadeza estão atrelados à condição feminina, construções estas marcadas na/pela história.

Desse lugar marcado em seus enunciados, a Luana, a Débora e a professora deixam ecoar, sem se darem conta de que o faziam, vozes alheias (BAKHTIN, 1993, 2003) apropriando-se de um discurso que faz parte de uma prática socialmente construída e culturalmente transmitida. Assim, temos presentes e explícitos sentidos e significados de feminilidade, como a fragilidade, a sensibilidade e a delicadeza.

\section{Episódio 4:}

O professor está trabalhando com o conteúdo lutas. Ele ensina alguns golpes e os/as alunos/as vivenciam os movimentos. No final da aula sobra um tempo e o professor deixa livre a atividade. Os meninos pedem a bola de futsal e vão jogar na quadra, enquanto algumas meninas vão jogar vôlei no espaço lateral à quadra e outras ficam conversando no pátio (este tipo de situação era recorrente nas aulas de Educação Física).

Enquanto os/as alunos/as jogam, o professor se aproxima de mim (conversa informal com o professor extraída do diário de campo):

Ele pergunta o que eu achei das aulas, da disciplina da turma. Falo que foram boas as aulas e aproveito para perguntar como os/as alunos/as se comportaram nas outras aulas com outros conteúdos. O professor fala que na ginástica eles/as se ajudaram bastante, fizeram as atividades juntos, mas que quando pega o esporte para trabalhar, os/as alunos/as logo se 
separam em grupos de meninas e meninos. ("Não tem jeito! Eles logo se separam.") Indago o que ele acha disso e ele relata que é difícil fazer os/as alunos/as jogarem juntos e sua justificativa para tal ocorrência se apóia na questão cultural, a qual alega que é muito forte, mas que aos poucos está tentando quebrar, desfazer algumas distinções, separações no que se refere às aulas de atividade física e vivências corporais.

Quando o professor deixa os/as alunos/as escolherem a atividade, podemos perceber que há uma diferenciação quanto ao tipo de prática e quanto à ocupação dos espaços por eles/as.

No que se refere às atividades, essa diferenciação de práticas entre meninas e meninos remete a uma história, na qual tal distinção era justificada pelas características padronizadas por regras sexuais e sociais, assegurando sentidos de feminilidade e de masculinidade, como graça, leveza, delicadeza, força e violência.

Quanto à utilização de espaços por meninos e meninas, temos que, ao ocuparem a quadra inteira, presentifica-se uma ideia de liderança e poder por parte dos meninos, assegurando também indícios de sentidos de masculinidade.

Na visão de Scharagrodsky (2004), a maioria dos homens tende a ocupar os espaços mais amplos e centrais, enquanto a maioria das mulheres - e também alguns homens - utiliza espaços reduzidos e marginais. Isso incide nas práticas corporais e/ou esportivas, separando, hierarquizando e reforçando concepções naturalizadas para cada sexo. E a utilização quase monopólica do espaço por parte da maioria dos homens reafirma e reproduz as expectativas tradicionais para o masculino, como ser forte, ser valente e, sobretudo, estar em controle da situação lúdico-esportiva.

Sousa e Altmann (1999), citando o estudo realizado por Altmann em uma escola de Belo Horizonte, afirmam que esta autora observou que os meninos ocupam espaços mais amplos que as meninas por meio do esporte, o qual está vinculado a imagens de uma masculinidade forte, violenta e vitoriosa. Elas também ressaltam que tal ocorrência parece acontecer em outras partes do mundo.

Diante do dizer do professor sobre a participação dos/as alunos/as nas aulas, temos que as interações estabelecidas entre eles/as se dão de diferentes formas. Estas formas podem sofrer influências de alguns fatores, entre os quais podemos citar o conteúdo trabalhado em aula. Assim, o professor destaca que, ao trabalhar a ginástica em suas aulas, houve uma interação muito grande entre meninos e meninas; todavia, o mesmo não acontece quando se trabalha com o esporte. Para ele, isso se deve à questão cultural, que está muito presente nas práticas corporais e dificulta a interação alunosalunas.

Mas, qual é a questão cultural a que o professor se refere? O que estaria por trás dos conteúdos mencionados pelo professor - a ginástica e o esporte, a ponto de promover uma interação diferenciada? Quais os motivos que levam meninas e meninos a separarem-se para a prática esportiva?

Apoiando-nos na história da Educação Física, podemos verificar que esses conteúdos foram tratados de maneiras diferentes. A ginástica, de certa forma, esteve sempre presente na educação dos meninos e das meninas, ao contrário dos esportes, que deveriam variar conforme o sexo do praticante. Em sua obra, Castellani Filho (1988) nos conta sobre os decretos e as deliberações acerca da nãopermissão à prática de lutas e esportes coletivos por parte das mulheres no início do século $X X$. Uma outra autora - Goellner (2003) -, ao falar do corpo feminino, tal como aparecia num periódico especializado das décadas de 1930 e 1940 - a Revista Educação Physica - traz registros desta em relação à oficialização de algumas proibições na tentativa de interditar algumas práticas corporais femininas ou a pretensão de que as mulheres venham delas participar, por constituírem desportos considerados violentos e não adaptáveis à feminilidade da mulher. Assim, Souza e Altmann (1999) consideram o esporte genereficado e genereficador.

As atividades distribuídas quanto ao sexo e a utilização diferenciada de espaços por meninas e meninos, homens e mulheres foram - e parece que continuam sendo - uma ocorrência em nossa sociedade e, particularmente, no espaço das aulas de Educação Física, evidenciando sentidos e significados de feminilidade e masculinidade. Isso leva a momentos de integração praticamente inexistentes entre meninas e meninos. Essa separação, que aos olhos de alguns aparenta ser algo natural, é muito mais uma construção cultural - o que é explicitado pelo professor e exposto no parágrafo anterior. De acordo com Vigotski (1993, 1995) e Bakhtin (1990, 1993, 2003), a cultura está presente na constituição do indivíduo, e esta é socialmente mediada através das inúmeras relações que estabelecemos, havendo a incorporação dos modos culturais de agir, pensar, de se relacionar com os outros e consigo mesmo.

\section{Episódio 5:}

A professora vai para a quadra com seus/suas alunos/as e propõe o jogo base quatro. No entanto, como o número de participantes não é o mesmo nas duas equipes, a professora fala que alguém poderá repetir o arremesso, de modo que iguale o número de arremessos entre as duas equipes. 
Professora: Conta quantos têm Bráulio, se não eu vou ter que aumentar esse time.

Bráulio: 13!

Professora: 13? Então um de vocês pode repetir.

Kaique: Deixa o Jessé.

Professora: Um pode repetir.

Jessé: Eu, Dona3!

Kaique: O Jessé.

Professora: Vocês é que vão escolher.

Jessé: Eu.

(Kaique e outros alunos falam juntos: "O Jessé.")

[...]

(A Martha arremessa a bola e sai correndo para a primeira base)

Jessé: Pára. Fica aí. Fica aí. Não sai. Não sai. Por nada. Só fica aí (pausa). Faz o que eu estou mandando. Só fica aí, não sai.

(Martha mantém-se na base).

\section{Episódio 6:}

Os/as alunos/as estão na quadra jogando base quatro. Enquanto a professora dá um tempo para as equipes trocarem de lugar arremessadores/as e lançador/a -, o Vitor organiza seus/suas colegas para a ordem de chutes. Ele coloca as meninas para irem primeiro e os meninos como os últimos a chutar.

No episódio 5 tem se configurado um processo de escolha de participante, o qual a professora deixa livre e aberto à equipe. Contudo, a escolha e decisão sobre quem repetirá 0 arremesso se dá somente entre os meninos que elegem outro menino - o Jessé. Logo em seguida, o Jessé é quem dá ordem para uma colega de equipe, sendo a ordem acatada. Tais acontecimentos levam-nos a pensar nas relações de gênero, indicando que, além das construções sociais estabelecidas entre mulheres e homens, ela implica também relações de poder. A esse respeito, Scraton (apud FARIA, 1998) argumenta que os meninos tendem a dominar as situações em que se tem um grupo misto. Ela destaca que tal dominação pode ser observada tanto pelo controle físico em atividades específicas como pelo controle verbal, em que os meninos, nas aulas mistas, tendem a dominar verbalmente e mandar nas meninas.

As mesmas relações podem ser verificadas no episódio seguinte, no qual o Vitor passa a organizar a sua equipe para a ordem dos arremessos. Mas, o que o leva a separar as meninas dos meninos? Por que as meninas são colocadas como as primeiras a arremessar? Essas indagações foram refletidas em um outro eixo temático não abordado neste artigo.

\footnotetext{
3 "Dona" é uma palavra utilizada pelos/as alunos/as para se referirem à professora. Já o professor não tem o mesmo tratamento, sendo chamado de professor mesmo.
}

No momento, expomos apenas que, em um dos seus trabalhos, Scharagrodsky (2007) salienta que ser forte e estar em controle da situação, tanto em relação ao tempo como à tática da atividade, são os requisitos básicos da masculinidade que entram em jogo durante as práticas corporais e, sobretudo, as esportivas. Essa masculinidade, segundo o autor, é um empreendimento que se legaliza constantemente e, ainda que se apresente às mulheres, está histórica e culturalmente dirigida aos homens.

Enfim, discursos ligados a práticas corporais e esportivas, proferidos por alunos/as, professor e professora, tentam (re)produzir uma verdade sobre os sujeitos e sobre seus corpos, resultando num saber que, traduzidos, revelam hierarquias entre indivíduos, concepções de feminilidade e masculinidade atribuídas e, às vezes, assumidas pelos/as próprios/as atores/atrizes sociais.

\section{Considerações}

Afastando-nos de uma visão de corpo apenas como algo biológico, enveredamos por uma perspectiva que contaria pensar o corpo, também, como algo produzido na e pela cultura, em um processo de construção social no qual the são conferidas diferentes marcas, em diferentes tempos, espaços, grupos sociais, conjunturas econômicas e políticas.

A reflexão sobre as relações entre sujeitos e grupos impõe que analisemos conflitos, disputas e jogos de poder historicamente implicados nessas relações. Supõe, também, reconhecer que vários embates culturais são levados a efeito em diversas situações cotidianas.

Certos comportamentos e usos corporais, movimentos, entre outros aspectos explicitados durante as análises, vão sendo (re)construídos por alunos/as, fazendo do campo da Educação Física Escolar um espaço de constituição de subjetividades através das produções e reproduções de sentidos de feminilidade e de masculinidade. E a administração desses sentidos determina modos distintos de participação nas aulas de Educação Física, principalmente no que se refere ao universo das práticas corporais e esportivas.

$\mathrm{Na}$ perspectiva de análise proposta, feminilidade e masculinidade carregam marcas de diferentes práticas sociais e culturais que são construídas através de discursos produzidos na sociedade e em meio às relações de poder estabelecidas por um sistema de significados dominante, que impõe formas de comportamento e naturaliza relações que são construídas.

Nas interações sociais, os significados e sentidos de dizeres, práticas e relações vão-se 
tecendo no movimento de articulação/negação/negociação (FONTANA, 2003) das possibilidades colocadas em jogo na dinâmica interativa, ocorrendo trocas simbólicas em um espaço marcado pela intersubjetividade. Desse modo, a linguagem, que atravessa e constitui a maioria das práticas, não apenas expressa relações, poderes, ela os institui. Ela não apenas veicula, mas produz e tenta fixar diferenças entre os sujeitos.

"Todos e todas nós participamos desses processos de produção, de forma mais ativa ou mais passiva, sofrendo-os ou impondo-os, a nós mesmos e aos outros com quem convivemos profissional e afetivamente" (MEYER, 2003, p.25).

Enfim, não creio em soluções definitivas para as tensões provocadas pela multiplicidade de sentidos e significados de feminilidade e masculinidade; entretanto, não há dúvidas de que essas tensões nos fazem refletir e buscar outros modos de ação.

\section{Referências}

ALTMANN, H. Construções e desconstruções de gênero e de sexualidade através do esporte. In: VII Seminário Fazendo Gênero. Florianópolis, 2006.

BAKHTIN, M. Marxismo e Filosofia da Linguagem. São Paulo: Hucitec, 5.ed., cap. 1 e 3, 1990 .

BAKHTIN, M. Marxismo e Filosofia da Linguagem. São Paulo: Hucitec, cap. 6 e 7, 1993.

BAKHTIN, M. Estética da Criação Verbal. São Paulo: Martins Fontes, p.261-306, 2003.

BAQUERO, R. Idéias centrais da teoria sóciohistórica. In: Vygotsky e a aprendizagem escolar. Porto Alegre: Artes Médicas, cap. 2, p.25-45, 1998.

DAOLIO, J. Da Cultura do Corpo. Campinas, SP: Papirus, 9.ed., 1995. 104p. (Coleção Corpo e Motricidade)

DAOLIO, J. Cultura: educação física e futebol. Campinas, SP: Editora da UNICAMP, 1997. 136p. (Coleção Livro-texto)

DAOLIO, J. Educação Física e o conceito de cultura. Campinas, SP: Autores Associados, 2004. (Coleção polêmicas do nosso tempo)

DAOLIO, J. A Educação Física Escolar como prática cultural: tensões e riscos. Pensar a Prática, 8/2, p.215-226, 2005.
FONTANA, R. A. C. Como nos tornamos professoras? 2.ed. Belo Horizonte: Autêntica, 2003. 208p.

GÓES, M. C. R.; CRUZ, M. N. Sentido, significado e conceito: notas sobre as contribuições de Lev Vigotski. In: Revista Proposições - Temas e Tendências na perspectiva histórico-cultural. Campinas. vol 17, nº 2 (50), p.32-45, mai/ago 2006.

LIMA, M. E. C. C. Os sentidos do trabalho: a educação continuada de professores. Belo Horizonte: Autêntica, p.19-31 e 33-57, 2005.

LOURO, G. L. Gênero, sexualidade e educação: uma perspectiva pós-estruturalista. Petrópolis, RJ: Vozes, 1997. 182p.

LURIA, A. R.. A atividade consciente do homem e suas raízes histórico-sociais. In: Curso de Psicologia Geral. Rio de Janeiro: Civilização Brasileira, v.1, p.71-84, 1979.

MARTINS, J. C. Vygotsky e o Papel das Interações Sociais na Sala de Aula: Reconhecer e Desvendar o Mundo. In: Série Idéias, n. 28, São Paulo: FDE, p. 111-122, 1997. Disponível em:

$<$ http//www.crmariocovas.sp.gov.br/pdf/idéias 28 p111-122 c.pdf>. Acesso em: 25 out 2006.

MEYER, D. E. Gênero e educação: teoria e política. In: LOURO, G. L.; NECKEL, J. F.; GOELLNER, S. Vilodre (orgs). Corpo, gênero e sexualidade: um debate contemporâneo na educação. Petrópolis, RJ: Vozes, p.09-27, 2003.

NOGUEIRA, Q. W. C. Educação Física, cultura e a produção de significados. Educar. Curitiba: Editora UFPR, n. 26, p.197-214, 2005.

SCHARAGRODSKY, P. A. Juntos pero no revueltos: la educación física mixta en clave de gênero. Cadernos CEDES. Campinas, v. 34, n. 121, p.59-76, jan-abril, 2004.

SCHARAGRODSKY, P. A. Masculinidades en acción: machos, maricas, subversivos y cómplices. El caso de la Educación Física argentina. In: RIBEIRO, Paula Regina Costa, et al. Corpo, gênero e sexualidade: discutindo práticas educativas. Rio Grande: Editora da FURG, p.18-30, 2007.

SCOTT, J. Gênero: uma categoria útil de análise histórica. Educação \& Realidade. Porto Alegre: Universidade Federal do Rio Grande do Sul, v.20, n.2, p.71-99, jul/dez, 1995.

SMOLKA, A. L. B. Internalização: seu significado na dinâmica dialógica. Educação \& Sociedade. Campinas, n. 42, agosto, 1992. 
SMOLKA, A. L. B. O (im)próprio e o

(im)pertinente na apropriação das práticas sociais. In: Cadernos CEDES. Campinas, v. 20, n. 50, 2000. Disponível em:

$<$ http://dx.doi.org/10.1590/S010132622000000100003>. Acesso em: 25 out 2006.

SOARES, C. L. Educação Física: raízes europeias e Brasil. Campinas, SP: Autores Associados, 2001, 2.ed. rev., 143p. (Coleção educação contemporânea)

SOUSA, E. S. Meninos, à marcha! Meninas, à sombra! A história do ensino da Educação Física em Belo Horizonte (1897-1994). 1994. Tese (Doutorado em Educacão) - Faculdade de Educação, Universidade Estadual de Campinas UNICAMP, Campinas, 1994.

SOUSA, E. S.; ALTMANN, H. Meninos e meninas: expectativas corporais e implicações na educação física escolar. Cadernos CEDES. Campinas, v. 19, n. 48, ago 1999. Disponível em: <http://dx.doi.org/10.1590/S010132621999000100004>. Acesso em: 12 Nov 2006.

VYGOTSKY, L. S. Pensamento e Linguagem. São Paulo: Martins Fontes, 1993. (Psicologia e pedagogia)

VYGOTSKY, L S. Génesis de las funciones psíquicas superiores. In: Problemas del desarrollo de la psique. Obras Escogidas, v.3. Madri: Visor, cap.5, p.139-168, 1995.

WERNECK, C. L. G. Dissimulação do uso social e político do corpo na Educação Física. In:

Coletânea. $3^{\circ}$ Congresso Latino-Americano de Esporte, Educação e Saúde no movimento humano. Cascavel: Gráfica Universitária, p.139149, 1996.

Este trabalho é proveniente do Exame de Defesa de Mestrado da autora, constituindo-se como um recorte da pesquisa "A produção de sentidos $\mathrm{e}$ significados de feminilidade e masculinidade em aulas de Educação Física Escolar", e foi financiado primeiramente pela Secretaria de Educação do Estado de São Paulo (Bolsa Mestrado) e posteriormente pela CAPES.

Esse artigo foi apresentado em Sessão Temática no VI Congresso Internacional de Educação Física e Motricidade Humana e XII Simpósio Paulista de Educação Física, realizado pelo Departamento de Educação Física do IB/UNESP Rio Claro, SP de 30/4 a 03/5 de 2009.
Endereço:

Vilma Canazart dos Santos

Rua Santos Dumont, 800 Jd. Alvorada

Sumaré SP Brasil

13170-586

Telefones: (19) 3873.2801 e 3873.1883

e-mail: vivicanazart@yahoo.com.br

Recebido em: 10 de fevereiro de 2009.

Aceito em: 03 de abril de 2009.

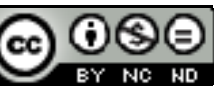

Motriz. Revista de Educação Física. UNESP, Rio Claro, SP, Brasil - elSSN: 1980-6574 - está licenciada sob Licença Creative Commons 